\title{
Catalytic Enantioselective Synthesis of Atropisomeric Biaryls via a Cation-Directed Nucleophilic Aromatic Substitution Reaction
}

\author{
Roly J. Armstrong and Martin D. Smith*
}

\begin{abstract}
A catalytic enantioselective nucleophilic aromatic substitution reaction that yields axially chiral biaryl derivatives in excellent yields with e.r. up to 97:3 has been developed. This process uses a chiral counterion to direct the addition of thiophenolate to a prochiral dichloropyrimidine via a tandem desymmetrization-kinetic resolution mechanism. The products can be derivatized to a range of atropisomeric structures without any reduction in enantioenrichment, offering access to unexplored chiral biaryl architectures.
\end{abstract}

The nucleophilic aromatic substitution reaction is a benchmark transformation within the field of synthetic organic chemistry, representing a powerful method for the construction of functionalized aromatic systems. ${ }^{[1]}$ Despite the significant synthetic utility of this reaction, few methods have been reported which enable the absolute stereochemical outcome of the transformation to be controlled $\mathrm{d}^{[2,3]}$ and to the best of our knowledge, few catalytic asymmetric variants have been disclosed. Jørgensen ${ }^{[4]}$ and Maruoka ${ }^{[5]}$ have elegantly demonstrated that trisubstituted enolates can be employed as nucleophiles in nucleophilic aromatic substitution reactions with electron-deficient aryl fluorides. Within both of these studies, the formation of the resulting quaternary stereogenic centre is controlled by a chiral phase-transfer catalyst. Zhu has carried out an asymmetric intramolecular cycloetherification reaction catalysed by a chiral Brønsted base. ${ }^{[6]}$ The product, an enantioenriched cyclophane, is rendered chiral by virtue of restricted rotation of a linker about a plane of chirality (Figure 1). Our aim was to build on these methods and develop a synthesis of atropisomeric biaryls, axially chiral compounds whose chirality originates from restricted rotation about a $\sigma$-bond. ${ }^{[7,8]}$ Given the central role occupied by atropisomeric materials within the fields of asymmetric catalysis and synthesis, ${ }^{[9]}$ enantioselective methods for the construction of such compounds are of great value. ${ }^{[10]}$ We reasoned that a chiral catalyst could effect a desymmetrizing nucleophilic aromatic substitution through discrimination in the displacement of enantiotopic leaving groups. ${ }^{[11,12]}$ It was envisaged that under asymmetric phase-transfer

[*] R. J. Armstrong, Prof. Dr M. D. Smith

Chemistry Research Laboratory, University of Oxford

12 Mansfield Road, Oxford, OX1 3TA, U.K

Fax: (+44) 1865285002

E-mail: martin.smith@chem.ox.ac.uk

Homepage: http://msmith.chem.ox.ac.uk/

[**] The European Research Council has provided financial support (FP7/2007-2013) / ERC grant agreement no. 259056. We gratefully acknowledge the Diamond Light Source for an award of instrument time on I19 (MT7768). We are very grateful to Dr Peter Knipe for assistance with X-ray crystallography.

Supporting information for this article is available on the WWW under http://dx.doi.org/10.1002/anie.201xxxxxx.

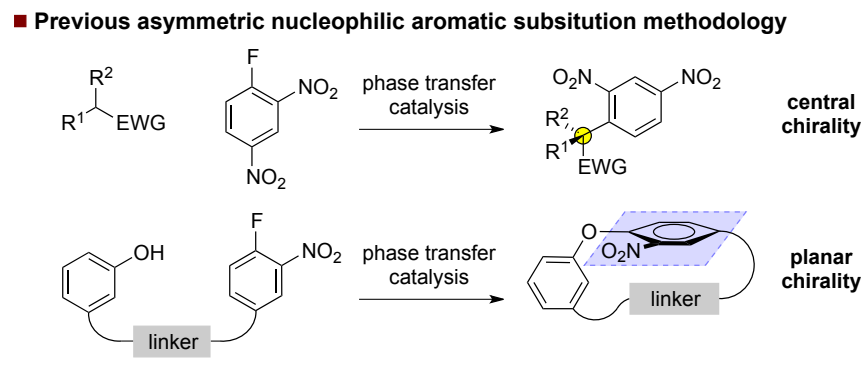

- This work: cation-directed atropselective nucleophilic aromatic subsitution

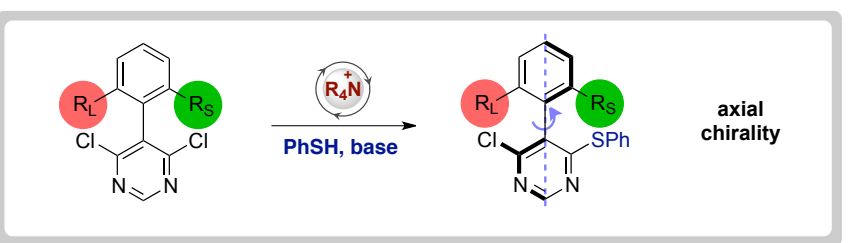

Figure 1. Previous work and strategy

conditions, the tight ion pair formed in a non-polar organic solvent between a deprotonated nucleophile and a chiral cation may allow such an event to be controlled (Figure 1). ${ }^{[13]}$ For such an approach to prove successful, we rationalized that the electrophile should possess (i) a plane of symmetry containing the biaryl axis, and (ii) an arene which is sufficiently electron-poor to undergo a nucleophilic aromatic substitution reaction under mild conditions. With these considerations in mind, we decided to investigate a sterically encumbered dichloropyrimidine electrophile $1{ }^{[14]}$ which was synthesized in four steps from commercially available starting materials. ${ }^{[15]}$ There is significant hindrance about the biaryl axis in this substrate, and hence we believed that substitution of one of the enantiotopic chlorine atoms would yield chiral material. Pleasingly, treatment of 1 with thiophenol in the presence of $\mathrm{KOH}$ and tetra- $\mathrm{N}$ butylammonium bromide afforded racemic $\mathbf{2}$ at room temperature. ${ }^{[16]}$
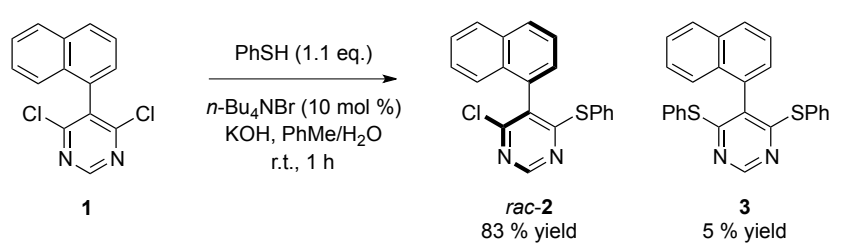

Scheme 1. Racemic phase-transfer catalysed nucleophilic aromatic substitution reaction. Conditions: 1 (1.0 eq.), $\mathrm{PhSH}$ (1.1 eq.), $n-\mathrm{Bu}_{4} \mathrm{NBr}(10 \mathrm{~mol} \%), 50 \%$ $\mathrm{KOH}$ (aq., w/w, 5.0 eq.), PhMe ([1] $\left.=0.1 \mathrm{~mol} \mathrm{dm}^{-3}\right)$.

Furthermore, this reaction proved to be selective for single vs. double addition, affording $\mathbf{2}$ and $\mathbf{3}$ in a 17:1 ratio respectively. Analytical chiral HPLC indicated that $\mathbf{2}$ was indeed atropisomeric, with no interconversion between enantiomers observed at room 
temperature on the timescale of the HPLC (Scheme 1). ${ }^{[17]}$ With these initial results in hand, we turned our attention to the asymmetric nucleophilic aromatic substitution reaction. Gratifyingly, upon treatment of $\mathbf{1}$ with a biphasic mixture of thiophenol, $\mathrm{N}$-benzylcinchonidinium chloride $\mathbf{4}$ and aqueous potassium carbonate in toluene we obtained $\mathbf{2}$ in a moderate, but promising 58:42 e.r. (Table 1 , entry 1 ). We next probed the efficacy of catalysts $\mathbf{5}$ and $\mathbf{6}$, derived from cinchonine and quinidine respectively, but little impact on the degree of enantioinduction was observed (Table 1, entries 2-3). We were therefore delighted to find that employing $N$-benzylquininium chloride 7 led to a significant improvement in enantioselectivity affording the product $\mathbf{2}$ in 87:13 e.r. (Table 1, entry 4 ). It is noteworthy that in these four examples (Table 1, entries 1-4), the major enantiomer possesses the same absolute configuration, irrespective of which pseudoenantiomer of the catalyst is employed.

Table 1. Optimization: asymmetric nucleophilic aromatic substitution reaction. ${ }^{[a]}$
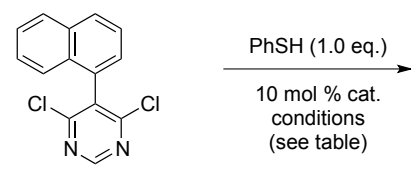

1

\begin{tabular}{|c|c|c|c|}
\hline Entry & Catalyst & Base & e.r..$^{[b]}$ \\
\hline 1 & 4 & $\mathrm{~K}_{2} \mathrm{CO}_{3}$ & $58: 42$ \\
\hline 2 & 5 & $\mathrm{~K}_{2} \mathrm{CO}_{3}$ & $61: 39$ \\
\hline 3 & 6 & $\mathrm{~K}_{2} \mathrm{CO}_{3}$ & $55: 45$ \\
\hline 4 & 7 & $\mathrm{~K}_{2} \mathrm{CO}_{3}$ & $87: 13$ \\
\hline 5 & 8 & $\mathrm{~K}_{2} \mathrm{CO}_{3}$ & $39: 61$ \\
\hline 6 & 9 & $\mathrm{~K}_{2} \mathrm{CO}_{3}$ & $46: 54$ \\
\hline 7 & 10 & $\mathrm{~K}_{2} \mathrm{CO}_{3}$ & $43: 57$ \\
\hline 8 & 11 & $\mathrm{~K}_{2} \mathrm{CO}_{3}$ & $43: 57$ \\
\hline 9 & 12 & $\mathrm{~K}_{2} \mathrm{CO}_{3}$ & $45: 55$ \\
\hline 10 & 7 & $\mathrm{Li}_{2} \mathrm{CO}_{3}$ & $85: 15$ \\
\hline 11 & 7 & $\mathrm{Cs}_{2} \mathrm{CO}_{3}$ & $86: 14$ \\
\hline 12 & 7 & $\mathrm{KOH}$ & $68: 32$ \\
\hline $13^{c}$ & 7 & $\mathrm{~K}_{2} \mathrm{CO}_{3}$ & $36: 64$ \\
\hline $14^{c}$ & 7 & $\mathrm{KOH}$ & $66: 34$ \\
\hline $15^{d}$ & 7 & $\mathrm{~K}_{2} \mathrm{CO}_{3}$ & $95: 5$ \\
\hline $16^{d, e}$ & 7 & $\mathrm{~K}_{2} \mathrm{CO}_{3}$ & $97: 3$ \\
\hline
\end{tabular}

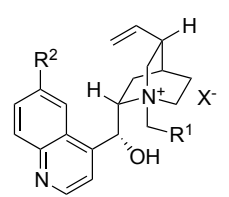

4: $\mathrm{R}^{1}=\mathrm{Ph} ; \mathrm{R}^{2}=\mathrm{H} ; \mathrm{X}=\mathrm{Cl}$

7: $\mathrm{R}^{1}=\mathrm{Ph} ; \mathrm{R}^{2}=\mathrm{OMe} ; \mathrm{X}=\mathrm{Cl}$

8: $\mathrm{R}^{1}=4-\mathrm{NO}_{2}-\mathrm{C}_{6} \mathrm{H}_{4} ; \mathrm{R}^{2}=\mathrm{OMe} ; \mathrm{X}=\mathrm{Br}$

9: $\mathrm{R}^{1}=3,5-\left(\mathrm{CF}_{3}\right)_{2}-\mathrm{C}_{6} \mathrm{H}_{3} ; \mathrm{R}^{2}=\mathrm{OMe} ; \mathrm{X}=\mathrm{Br}$

10: $R^{1}=2,3,4-\mathrm{F}_{3}-\mathrm{C}_{6} \mathrm{H}_{2} ; \mathrm{R}^{2}=\mathrm{OMe} ; \mathrm{X}=\mathrm{Br}$

11: $\mathrm{R}^{1}=3-\mathrm{Me}-\mathrm{C}_{6} \mathrm{H}_{4} ; \mathrm{R}^{2}=\mathrm{OMe} ; \mathrm{X}=\mathrm{Br}$

12: $\mathrm{R}^{1}=2-\mathrm{Me}_{-} \mathrm{C}_{6} \mathrm{H}_{4} ; \mathrm{R}^{2}=\mathrm{OMe} ; \mathrm{X}=\mathrm{Br}$

[a] Conditions: 1 (0.073 mmol), $\mathrm{PhSH}$ (1.0 eq.), catalyst (10 mol \%), base (33\% aq., w/w, 5.0 eq.), PhMe ([1] $=0.1 \mathrm{~mol} \mathrm{dm}^{-3}$ ), r.t., 24 h. [b] e.r. determined by stationary phase chiral HPLC. [c] solid base (1.0 eq.) was used. [d] $\mathrm{CCl}_{4}$ was used as the reaction solvent. [e] 1.1 eq. of $\mathrm{PhSH}$ was used, reaction time $48 \mathrm{~h}$.

Variation of the steric and electronic nature of the $N$-pendant group of the catalyst had a significant impact upon selectivity, reversing the absolute configuration of the major enantiomeric product (relative to entries 1-4), along with significantly reduced enantioselectivities (Table 1, entries 5-9). A range of aqueous carbonate bases proved equally effective at promoting the reaction, although aqueous hydroxide and solid bases generated $\mathbf{2}$ with inferior stereoselectivity (Table 1, entries 10-14). The use of carbon tetrachloride, which has previously been demonstrated to be an effective solvent for asymmetric phase-transfer catalyzed reactions of thiol nucleophiles, led to a further increase in enantioselectivity to 95:5 e.r. (Table 1, entry 15 ). ${ }^{[18]} \mathrm{We}$ found that increasing the number of equivalents of thiophenol from 1.0 to 1.1 also led to increased enantioenrichment, affording 3 in 97:3 e.r. (Table 1, entry 16).

With conditions for a highly enantioselective asymmetric nucleophilic aromatic substitution reaction established, we set out to examine the generality of the process by varying the electrophile. Substitution of the naphthyl group in the 4-position was well tolerated in the case of a methyl group, affording 13 in 96:4 e.r., and subsequently the absolute configuration of $\mathbf{1 3}$ was established by $\mathrm{X}$ ray crystallography. ${ }^{[19]}$ When a bromine substituent was incorporated into the same position, the selectivity was somewhat diminished, and the product $\mathbf{1 4}$ was isolated in 87:13 e.r.

Table 2. Asymmetric nucleophilic aromatic substitution reaction. ${ }^{[a]}$

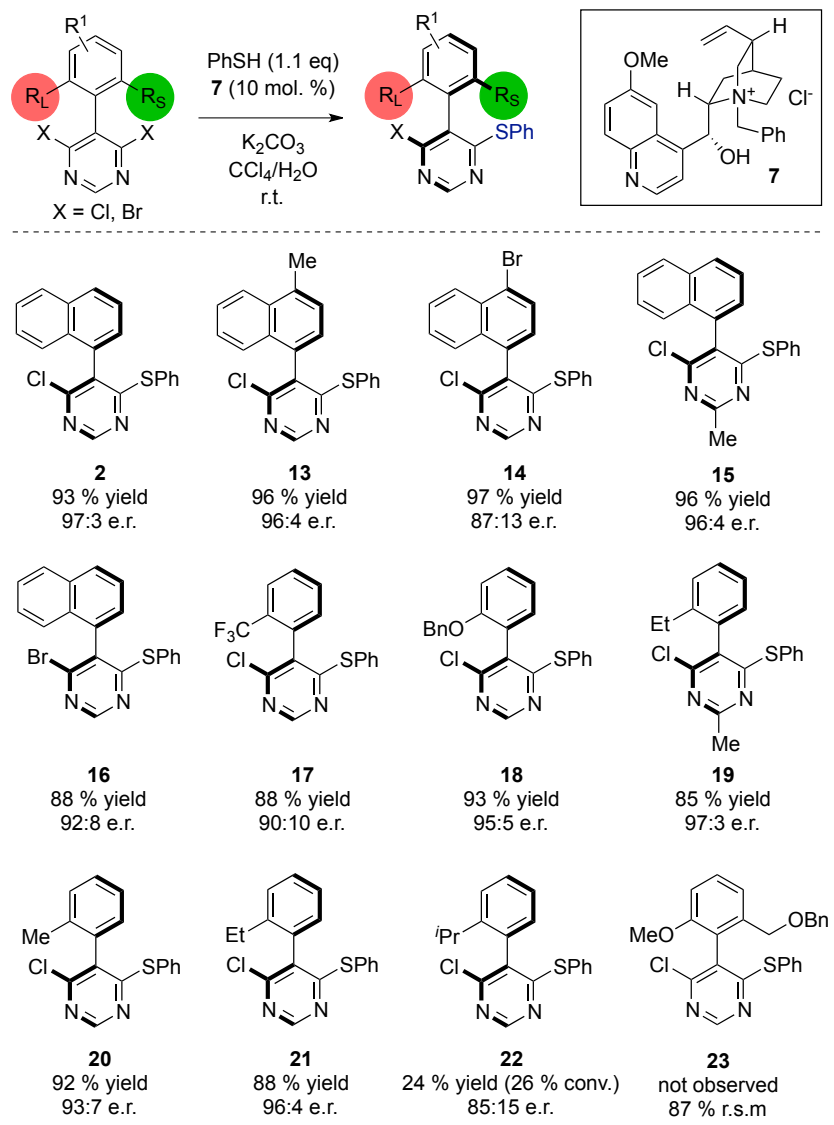

[a] Conditions: $\mathrm{PhSH}$ (1.1 eq.), 7 (10 mol \%), $50 \% \mathrm{~K}_{2} \mathrm{CO}_{3}$ (aq., w/w, 5.0 eq.), $\mathrm{CCl}_{4}\left([\right.$ electrophile $\left.]=0.1 \mathrm{~mol} \mathrm{dm}^{-3}\right), 48 \mathrm{~h}$. Yields refer to isolated materials; e.r. determined by stationary phase chiral HPLC.

It was also possible to introduce a substituent onto the pyrimidine ring - a substrate with a 2-methyl group participated in the desired reaction, forming $\mathbf{1 5}$ in high yield with excellent enantioselectivity. We also found that the leaving group could be varied from chlorine to bromine, affording 16 in $88 \%$ yield and 92:8 e.r. Substrates with a single ortho-substituted aromatic ring are also interesting synthetic targets, provided that the barrier to rotation about the aryl-aryl bond is sufficiently high to avoid racemization of the product. We synthesized a series of compounds with increasingly bulky orthogroups and were pleased to find that under our previously optimized 
conditions 17, 18, 19, 20 and 21 were all formed in high yields with good to excellent enantioselectivities. The steric nature of the electrophile appears to have some impact upon reactivity - the extremely hindered ortho-isopropyl substituted example $\mathbf{2 2}$ only reached $26 \%$ conversion after $48 \mathrm{~h}$, albeit still with good enantioselectivity. This trend continues, with more hindered 2,6disubstituted electrophiles as exemplified by $\mathbf{2 3}$, which proved unreactive under the reaction conditions. All compounds in Table 2 display a remarkably high barrier to rotation about the aryl-aryl bond. For instance, 19 racemizes in solution with a $\tau_{1 / 2}$ rac $>0.6$ years. A solid sample of $\mathbf{1 9}$ exhibited showed no racemization after several months at room temperature. ${ }^{[20]}$

During reaction optimization, we had noted that employing a slight excess of thiophenol led to increased levels of enantioselectivity.

Table 3. Increased thiol loading in asymmetric nucleophilic aromatic substitution reaction. $^{[\mathrm{a}]}$

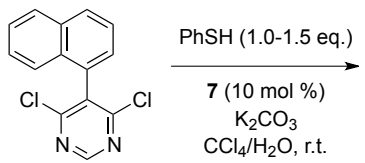

1

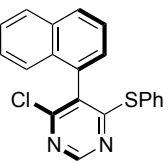

2

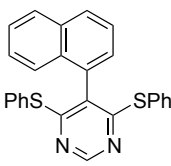

3

\begin{tabular}{llccc}
\hline Entry & eq. PhSH & yield 2 [\%] & e.r. 2 & yield 3 [\%] \\
\hline 1 & 1.0 & $98^{[\mathrm{b}]}$ & $95: 5$ & - \\
2 & 1.1 & 93 & $97: 3$ & 6 \\
3 & 1.3 & 90 & $98: 2$ & 8 \\
4 & 1.5 & 93 & $98: 2$ & 7 \\
\hline
\end{tabular}

[a] Conditions: 1 (0.18 mmol), $\mathrm{PhSH}, 7$ (10 mol \%), $50 \% \mathrm{~K}_{2} \mathrm{CO}_{3}$ (aq., w/w, 5.0 eq.), $\mathrm{CCl}_{4}\left([1]=0.1 \mathrm{~mol} \mathrm{dm}^{-3}\right), 48 \mathrm{~h}$. Yields refer to isolated material; e.r. determined by stationary phase chiral HPLC. [b] $94 \%$ conversion of SM.

We investigated this effect further by subjecting $\mathbf{1}$ to various loadings of thiol (Table 3). A clear trend was observed - an increased excess of thiophenol led to $\mathbf{2}$ in improved enantioselectivity along with a corresponding increase in the amount of double addition product 3 .

(a) Kinetic resolution of rac-2 ${ }^{\text {[a] }}$

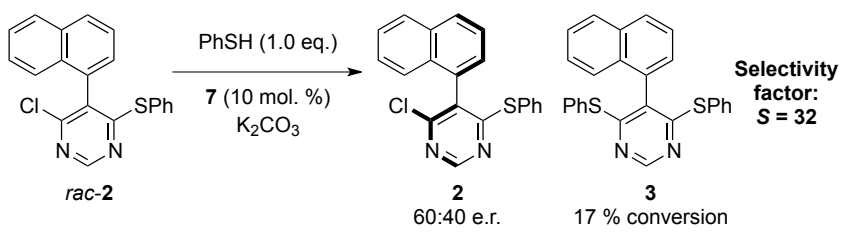

(b) Tandem desymmetrization-kinetic resolution
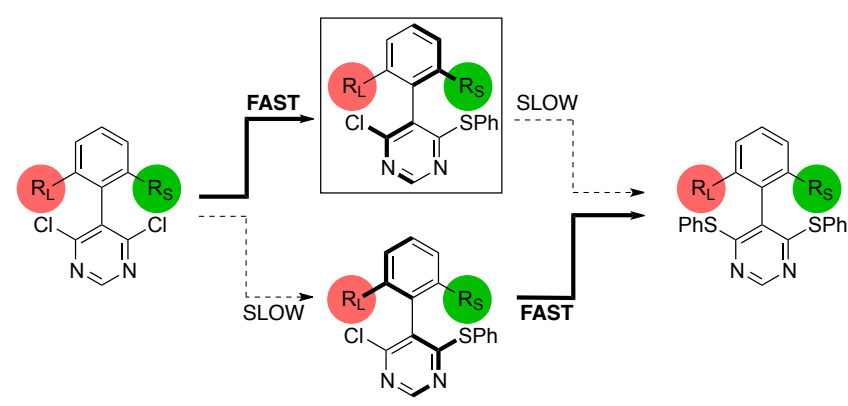

Scheme 2. Kinetic resolution. [a] Conditions: rac-2 (1.0 eq.), $\mathrm{PhSH}$ (1.1 eq.), 7 (10 mol \%), $50 \% \mathrm{~K}_{2} \mathrm{CO}_{3}$ (aq., w/w, 5.0 eq.), $\mathrm{CCl}_{4}\left([\mathrm{rac}-2]=0.1 \mathrm{~mol} \mathrm{dm}^{-3}\right)$, r.t., 6 d. Conversion and e.r. determined by stationary phase chiral HPLC.
We were interested in the origin of this effect, speculating that the excess nucleophile remaining after the first addition may preferentially scavenge the minor enantiomer of the product ent-2 from the system in a kinetic resolution. ${ }^{[21]}$ To test this hypothesis, we subjected rac-2 to optimized asymmetric conditions and observed $17 \%$ conversion to 3 . The starting material 2 was found to be enantioenriched (60:40 e.r.), and the major enantiomer was $(R)$-, as obtained previously (Scheme 2a). This strongly suggests that a desymmetrization-kinetic resolution effect is responsible for the enhanced enantioselectivity observed with excess thiol (Scheme 2b). ${ }^{[2]}$ This is consistent with the seminal work of Hayashi, who observed a similar phenomenon in the transition-metal catalysed enantioselective desymmetrization of pro-stereogenic biaryls. ${ }^{[12]}$

To further expand the synthetic utility of the reaction, we wished to demonstrate that the products of the reaction (as exemplified by 2 ) can be selectively manipulated. The aryl sulfide in 2 could be oxidized with meta-chloroperbenzoic acid to the corresponding sulfone $\mathbf{2 4}$ in $99 \%$ yield with no erosion of enantiomeric purity. The products of the nucleophilic aromatic substitution reaction 13-22 contain an activated aryl chloride, which serves as a useful handle for further functionalization. A range of $S$-, $\mathrm{N}$ - and $\mathrm{O}$ - nucleophiles were able to undergo nucleophilic aromatic substitution at this position, leading to the corresponding products 25, 26 and 27, with no change in enantiomeric ratio. ${ }^{[23]}$ We were also able to carry out a Suzuki-Miyaura cross-coupling reaction with phenylboronic acid to afford the product $\mathbf{2 8}$ in $96 \%$ yield, again with no loss of stereochemical integrity. We found that organolithium reagents add selectively to the 2-position of the pyrimidine; treatment with $n$-BuLi followed by in-situ oxidation with DDQ, afforded 29 in excellent yield, with no reduction in enantioenrichment (Scheme 3).
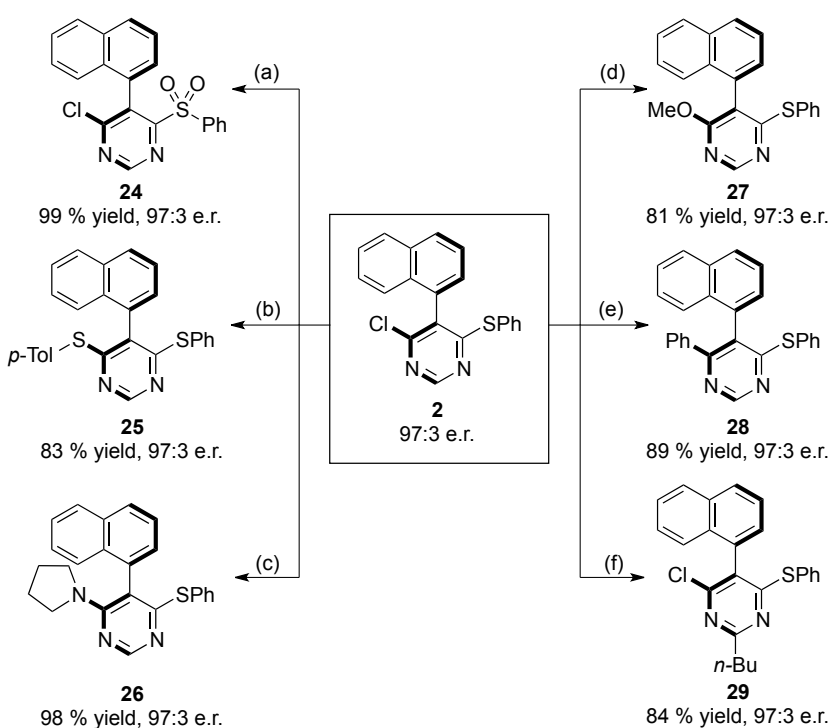

Scheme 3. Derivatization of substituted products. Conditions: (a) $m$ CPBA (5.0 eq.), $\mathrm{CH}_{2} \mathrm{Cl}_{2}$, r.t., $16 \mathrm{~h}$ (b) $p$-thiocresol (1.3 eq.), $50 \% \mathrm{KOH}$ (aq., w/w, 10 eq.), $n$ $\mathrm{Bu}_{4} \mathrm{NBr}\left(10 \mathrm{~mol} \%\right.$ ), PhMe, r.t., 16 h. (c) pyrrolidine (5.0 eq.), $\mathrm{NEt}^{\prime} \mathrm{Pr}_{2}$ (5.0 eq.), $\mathrm{DMF}$, r.t., 3 h. (d) $\mathrm{MeOH}\left(5.0\right.$ eq.), $\mathrm{CsOH} . \mathrm{H}_{2} \mathrm{O}$ (s) (2.0 eq.), $n-\mathrm{Bu}_{4} \mathrm{NHSO}_{4}(10$ mol \%), PhMe, r.t. 24 h. (e) $\mathrm{PhB}(\mathrm{OH})_{2}$ (1.5 eq.), $\mathrm{Pd}\left(\mathrm{PPh}_{3}\right)_{4}(10 \mathrm{~mol} \%), \mathrm{K}_{2} \mathrm{CO}_{3}$ (2.0 eq.), PhMe, $75^{\circ} \mathrm{C}, 16$ h. (f) $n$-BuLi (1.1 eq.), THF, $-78^{\circ} \mathrm{C}, 10 \mathrm{~min}$, then $\mathrm{H}_{2} \mathrm{O}$, DDQ (1.1 eq.), $-78^{\circ} \mathrm{C}$ to r.t., $5 \mathrm{~min}$.

From a mechanistic perspective, we believe that the asymmetric nucleophilic aromatic substituition reaction occurs via an interfacial process, as described by Mąkosza. ${ }^{[24]}$ Deprotonation of the thiol at the interface followed by ion exchange with the catalyst generates a 
lipophilic ion pair which moves into the organic phase to react with the dichloropyrimidine. The nucleophilic substitution event itself likely takes place via a two-step process involving formation and subsequent collapse of a Meisenheimer complex. ${ }^{[25]}$ It is intriguing to consider whether the formation of such a complex, which possesses both a stereogenic centre and axis, occurs diastereoselectively; we are currently investigating this possibility.

In conclusion, we have developed a selective and efficient approach to the asymmetric synthesis of axially chiral biaryls via a desymmetrizing nucleophilic aromatic substitution process. We have identified that the enantioselectivity of this process is reinforced by a kinetic resolution event which transforms the minor enantiomer into an achiral species. The resulting chiral biaryl products contain a second reactive aryl halide which can be readily derivatized affording a range of new atropisomeric biaryl compounds.

Received: ((will be filled in by the editorial staff)) Published online on ((will be filled in by the editorial staff)).

Keywords: atropisomerism · axial chirality $\cdot$ nucleophilic aromatic substitution $\cdot$ phase-transfer catalysis $\cdot$ desymmetrization

[1] a) E. Buncel, J. M. Dust, F. Terrier, F. Chem. Rev. 1995, 95, 2261; b) F. Terrier, Modern Nucleophilic Aromatic Substitution, Wiley VCH, Weinheim, 2013.

[2] For examples of diastereoselective $\mathrm{S}_{\mathrm{N}} \mathrm{Ar}$ reactions, see: a) A. I Meyers, K. A. Lutomski, J. Am. Chem. Soc. 1982, 104, 879; b) J. M. Wilson, D. J. Cram J. Am. Chem. Soc. 1982, 104, 881; c) K. C. Nicolaou, H. Li, C. N. C. Boddy, J. M. Ramanjulu, T.-Y. Yue, S. Natarajan, X.-J. Chu, S. Bräse, F. Rübsam, Chem. Eur. J. 1999, 5 , 2584; d) S. Sen, V. R. Potti, R. Surakanti, Y. L. N. Murthy, R. Pallepogu, Org. Biomol. Chem. 2011, 9, 358.

[3] For an interesting approach to enantioselective nucleophilic aromatic substitution employing superstoichiometric small-molecule chiral selectors see: S. E. Snyder, A. B. Shvets, W. H. Pirkle, Helv. Chim. Acta. 2002, 85, 3605

[4] a) M. Bella, S. Kobbelgaard, K. A. Jørgensen, J. Am. Chem. Soc. 2005 , 127,3670 ; b) S. Kobbelgaard, M. Bella, K. A. Jørgensen, J. Org. Chem. 2006, 71, 4980.

[5] a) S. Shirakawa, K. Yamamoto, T. Tokuda, K. Maruoka, Asian J. Org. Chem. 2014, 3, 433; b) S. Shirakawa, K. Koga, T. Tokuda, K. Yamamoto, K. Maruoka, Angew. Chem. Int. Ed. 2014, 53, 6220; Angew. Chem. 2014, 126, 6334

[6] G. Islas-Gonzalez, M. Bois-Choussy, J. Zhu, Org. Biomol. Chem. 2003, 1,30 .

[7] For reviews on axially chiral compounds as catalysts, see: a) C. Rosini, L. Franzini, A. Raffaelli, P. Salvadori, Synthesis 1992, 503; b) M. McCarthy, P. J. Guiry, Tetrahedron 2001, 57, 3809.

[8] For different organocatalytic approaches to the synthesis of atropisomeric materials see: a) J. Gustafson, D. Lim, S. J. Miller, Science 2010, 328, 1251; b) K. T. Barrett, S. J. Miller, J. Am. Chem. Soc. 2013, 135, 2963; c) S. Brandes, B. Niess, M. Bella, A. Prieto, J. Overgaard, K. A. Jørgensen, Chem. Eur. J. 2006, 12, 6039.

[9] a) J. Clayden, W. J. Moran, P. J. Edwards, S. R. LaPlante, Angew. Chem. Int. Ed. 2009, 48, 6398; b) A. Zask, J. Murphy, G. A. Ellestad, Chirality 2013, 25, 265.
[10] For reviews of atropselective syntheses of biaryls, see: a) G. Bringmann, A. J. Price Mortimer, P. A. Keller, M. J. Gresser, J. Garner, M. Breuning, Angew. Chem. Int. Ed. 2005, 44, 5384; b) T. W. Wallace, Org. Biomol. Chem. 2006, 4, 3197; c) M. C. Kozlowski, B. J. Morgan, E. C. Linton, Chem. Soc. Rev. 2009, 38, 3193.

[11] For other examples of desymmetrizing atropselective reactions, see: a) L. M. Engelhardt, W.-P. Leung, C. L. Raston, G. Salem, P. Twiss, A. H. White, J. Chem. Soc. Dalton Trans. 1988, 2403; b) T. Harada, T. M. T. Tuyet, A. Oku, Org. Lett. 2000, 2, 1319; c) T. Matsumoto, T. Konegawa, T. Nakamura, K. Suzuki, Synlett 2002, 122; d) K. Okuyama, K. Shingubara, S.-I. Tsujiyama, K. Suzuki, T. Matsumoto, T., Synlett 2009, 941; e) Q. Perron, A. Alexakis, Adv. Synth. Catal. 2010, 2611; f) Yuan, A. Page, C. P. Worrall, F. Escalettes, S. C. Willies, J. J. W. McDouall, N. J. Turner, J. Clayden, Angew. Chem. Int. Ed. 2010, 49, 7010; g) K. Mori, Y. Ichikawa, M. Kobayashi, Y. Shibata, M. Yamanaka, T. Akiyama, J. Am. Chem. Soc. 2013, 135, 3964; h) M. Carbó López, G. Royal, C. Philouze, P. Y. Chavant, V. Blandin, Eur. J. Org. Chem. 2014, 4884; i) S. Staniland, B. Yuan, N. Giménez-Agulló, T. Marcelli, S. C. Willies, D. M. Grainger, N. J. Turner, J. Clayden, Chem. Eur. J. 2014, DOI: 10.1002/chem.201404509.

$[12]$ a) T. Hayashi, S. Niizuma, T. Kamikawa, N. Suzuki, Y. Uozumi, $J$. Am. Chem. Soc. 1995, 117, 9101; b) T. Kamikawa, Y. Uozumi, T. Hayashi, Tetrahedron Lett. 1996, 37, 3161; c) T. Kamikawa, T. Hayashi, Tetrahedron 1999, 55, 3455.

[13] For selected reviews of asymmetric phase-transfer catalysis, see: a) M. J. O'Donnell, Acc. Chem. Res. 2004, 37, 506; b) T. Ooi, K. Maruoka, Angew. Chem., Int. Ed. 2007, 46, 4222; c) S. Shirakawa, K. Maruoka, Angew. Chem., Int. Ed. 2013, 52, 4312.

[14] For a discussion of the activating effect of aza-substitution on $\mathrm{S}_{\mathrm{N}} \mathrm{Ar}$ reactions see ref 1(b) and G. Illuminati, F. Stegel, Adv. Heterocycl. Chem. 1983, 34, 305.

[15] M. H. Bolli, C. Boss, C. Binkert, S. Buchmann, D. Bur, P. Hess, M. Iglarz, S. Meyer, J. Rein, M. Rey, A. Treiber, M. Clozel, W. Fischli, T. Weller, J. Med. Chem. 2012, 55, 7849 .

[16] Reaction of 1 with a range of $N-, O$ - and $C$ - nucleophiles proved relatively sluggish.

[17] In samples which the enantiomers interconvert on the timescale of the HPLC, a raised plateau between the separate enantiomer peaks is present; no such effect was observed for $\mathbf{2}$. For a discussion of this effect, see: O. Trapp, Chirality 2006, 18, 489.

[18] Z.-B. Luo, X.-L. Hou, L.-X. Dai, Tetrahedron: Asymm. 2007, 18, 443.

[19] X-ray data for $\mathbf{1 3}$ have been submitted to the Cambridge Crystallographic Data Centre (CCDC 1019025). We tentatively speculate that the absolute configuration of the major enantiomer of substrates in Table 2 is the same as for 13. This is consistent with the order of elution of the major enantiomer by chiral HPLC for 13-22. However, absolute configuration of $\mathbf{1 4 - 2 3}$ cannot be unequivocally demonstrated with the data we possess.

[20] The barrier to rotation for $\mathbf{1 9}$ is estimated to be $28 \mathrm{kcal} \mathrm{mol}^{-1}$; see supplementary information for full details.

[21] For rationalization of this effect see: S. L. Schreiber, T. S. Schreiber, D. B. Smith, J. Am. Chem Soc. 1987, 109, 1525.

[22] a) H. B. Kagan, J. C. Fiaud, In Topics in Stereochemistry; John Wiley \& Sons: New York, 1988; Vol. 18, p. 249; b) J. M. Goodman, A.-K. Köhler, S. C. M. Alderton, Tetrahedron Lett. 1999, 40, 8715.

[23] For an insightful study on the application of chiral non-racemic palladium catalysts to cross-coupling atropisomeric aryl bromides see: J. L. Gustafson, D. Lim, K. T. Barrett, S. J. Miller, Angew. Chem. Int. Ed. 2011, 50, 5125 .

[24] M. Makkosza, E. Bialecka, Tetrahedron Lett. 1977, 18, 183.

[25] F. Bunnett, R. E. Zahler, Chem. Rev. 1951, 49, 273. 


\section{Asymmetric catalysis}

Roly J. Armstrong and Martin D.

Smith*

Page - Page

Catalytic Enantioselective Synthesis of Atropisomeric Biaryls via a Cation-

Directed Nucleophilic Aromatic

Substitution Reaction

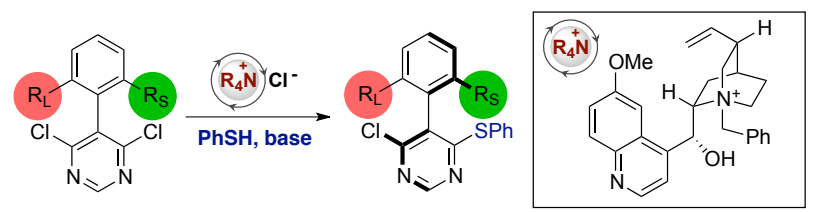

Asymm-Desymm: A catalytic asymmetric nucleophilic aromatic substitution reaction that yields axially chiral biaryls in excellent yields with e.r. up to 97:3 has been developed. This process uses a chiral counterion to direct the addition of thiophenolate to an achiral dichloropyrimidine via a tandem desymmetrizationkinetic resolution mechanism. The products can be derivatized to a range of atropisomeric structures without any reduction in enantioenrichment, offering access to unexplored chiral biaryl architectures. 